\title{
Visitation policies and practices in US ICUs
}

\author{
Vincent Liu ${ }^{*}$, Julia Lindeman Read², Elizabeth Scruth ${ }^{3}$ and Eugene Cheng ${ }^{4}$
}

\begin{abstract}
Introduction: Prior reports suggest that restrictive ICU visitation policies can negatively impact patients and their loved ones. However, visitation practices in US ICUs, and the hospital factors associated with them, are not well described.

Methods: A telephone survey was made of ICUs, stratified by US region and hospital type (community, federal, or university), between 2008 and 2009. Hospital characteristics were self-reported and included the hospitals' bed number, critical care unit number, and presence of ICU leadership. Hospital and ICU visitation restrictions were based on five criteria: visiting hours; visit duration; number of visitors; age of visitors; and membership in the patient's immediate family. Hospitals or ICUs without restrictions had open visitation policies; those with any restriction had restrictive policies.

Results: The study surveyed 606 hospitals in the Northeast (17.0\%), Midwest (26.2\%), South (36.6\%), and West (20.1\%) regions; most were community hospitals $(n=401,66.2 \%)$. The mean hospital size was $239 \pm 217$ beds; the mean percentage of ICU beds was $11.6 \% \pm 13.4 \%$. Hospitals often had restrictive hospital $(n=463,76.4 \%)$ and ICU $(n=543,89.6 \%)$ visitation policies. Many ICUs had $\geq 3$ restrictions $(n=375 ; 61.9 \%)$, most commonly related to visiting hours and visitor number or age. Nearly all ICUs allowed visitation exceptions ( $n=474 ; 94.8 \%)$. ICUs with open policies were more common in hospitals with < 150 beds. Among restrictive ICUs, the bed size, hospital type, number of critical care units, and ICU leadership were not associated with the number of restrictions. On average, hospitals in the Midwest had the least restrictive policies, while those in the Northeast had the most restrictive.

Conclusion: In 2008 the overwhelming majority of US ICUs in this study had restrictive visitation policies. Wide variability in visitation policies suggests that further study into the impact of ICU visitations on care and outcomes remains necessary to standardize practice.
\end{abstract}

\section{Introduction}

Critical illness and intensive care have a profound and traumatic impact on the health and well-being of patients and their loved ones [1-3]. Previous reports suggest that many patients in the ICU are separated from their families and loved ones by widespread restrictive visitation policies that can negatively impact care and recovery [3-6]. However, limited data exist about the scope and variability of ICU visitation policies and practices across the United States as well as the hospital factors that influence them [7-10]. In this study, we conducted a survey of US ICUs to describe the current landscape of ICU visitation policies. We further

\footnotetext{
* Correspondence: Vincent.X.Liu@KP.org

'Kaiser Permanente Division of Research and Systems Research Initiative, 2000 Broadway (Webster Annex), Oakland, CA 94612, USA

Full list of author information is available at the end of the article
}

aimed to evaluate whether key hospital characteristics were associated with visitation restrictions.

\section{Materials and methods}

Based on the American Hospital Association 2008 Hospital Survey Database, we grouped hospitals as either university-affiliated hospitals, federal government (Veterans Health Administration) hospitals, or nonfederal and nonuniversity community hospitals. We aimed to survey all university and government hospitals with an ICU. We then stratified community hospitals (which make up the majority of US hospitals) based on their location in US regions (Midwest, Northeast, South, and West) and aimed to survey an equal percentage of eligible hospitals (25\%) within each region to achieve a total of 670 surveyed hospitals (of an estimated 3,228 ICUs in the United States) [11].

\section{Biomed Central}


For each hospital, we contacted the ICU leadership, if available, or ICU nursing staff familiar with visitation policies to conduct the telephone survey from 2008 to 2009. If a hospital's ICU personnel could not be identified or declined survey participation, the next hospital in the randomly generated sample by strata was surveyed. The 17-question survey ascertained hospital characteristics including each hospital's self-reported number of beds (total and ICU) and critical care units; if numbers were reported as a range (for example, 25 to 30 beds), we selected the mean value ( 28 beds). We calculated the percentage of critical care beds within each hospital (ICU bed percentage). We also ascertained the presence or absence of ICU leadership (medical director or clinical nurse specialist). Clinical nurse specialists typically have received training at the level of a master's degree and often take a lead role in staff education, protocol development, and standardizing nursing care based on current evidence.

We assessed visitation policies based on whether the hospital or ICU placed restrictions based on a total of five criteria: visiting hours; visit duration; number of visitors; age of visitors; and membership in the patient's immediate family. We designated hospitals with zero restrictions as having open visitation policies and those with any restriction as having a restricted policy. We also determined whether exceptions to the visitation policies were allowed within the ICU.

We described data as the number (frequency) and mean \pm standard deviation. We used Spearman's correlation coefficient to assess the intra-hospital correlation between the number of hospital and ICU visitation restrictions. To determine the association between hospitals' ICU visitation policies and characteristics, we included key hospital characteristics as predictor variables in univariable and multivariable linear regression where the number of ICU restrictions was the outcome variable. Analyses were conducted using Stata/SE 11.2 (StataCorp. LP, College Station, TX, USA).

\section{Results}

\section{Hospital characteristics}

We contacted 695 hospitals; $87.2 \%(n=606)$ completed the survey. Hospitals were located in 50 states and the District of Columbia. More than one-third were from the South $(n=222,36.6 \%)$ and most were community hospitals $(n=401,66.2 \%$; Table 1$)$. The mean hospital bed size was $239 \pm 217$ (median, 159). The mean ICU bed percentage was $11.6 \pm 13.4 \%$; the mean number of ICUs per hospital was $2.1 \pm 1.8$. A total of $62.2 \%$ of ICUs had a medical director and $39.0 \%$ had a clinical nurse specialist.

Table 1 Survey hospital characteristics

\begin{tabular}{|c|c|c|c|c|}
\hline \multirow[b]{2}{*}{ Variable } & \multicolumn{4}{|c|}{ Hospital region } \\
\hline & Northeast & Midwest & South & West \\
\hline Number & $103(17.0)$ & $159(26.2)$ & $222(36.6)$ & $122(20.1)$ \\
\hline \multicolumn{5}{|l|}{ Hospital type } \\
\hline Community & $55(53.4)$ & $102(64.2)$ & $154(69.4)$ & $90(73.8)$ \\
\hline Federal & $26(25.2)$ & $31(19.5)$ & $40(18.0)$ & $18(14.8)$ \\
\hline University & $22(21.4)$ & $26(16.4)$ & $28(12.6)$ & $14(11.5)$ \\
\hline \multicolumn{5}{|l|}{ Hospital bed number } \\
\hline$<100$ & $16(15.5)$ & $56(35.2)$ & $55(24.8)$ & $39(32.0)$ \\
\hline 100 to 299 & $45(43.7)$ & $58(36.5)$ & $101(45.5)$ & $53(43.4)$ \\
\hline 300 to 499 & $10(9.7)$ & $26(16.4)$ & $34(15.3)$ & 19 (15.6) \\
\hline$>500$ & $22(21.4)$ & $16(10.1)$ & $28(12.6)$ & $9(7.4)$ \\
\hline Not reported & $10(9.7)$ & $3(1.9)$ & $4(1.8)$ & $2(1.6)$ \\
\hline ICU number & $2.4 \pm 2.1$ & $2.0 \pm 1.8$ & $2.0 \pm 1.6$ & $2.0 \pm 1.8$ \\
\hline \multicolumn{5}{|l|}{ ICU bed number } \\
\hline$<10$ & $16(15.5)$ & $56(35.2)$ & $44(19.8)$ & $26(21.3)$ \\
\hline 10 to 15 & 34 (33.0) & $35(22.0)$ & 88 (39.6) & $32(26.2)$ \\
\hline 16 to 39 & $24(23.3)$ & $40(25.2)$ & $59(26.6)$ & 41 (33.6) \\
\hline$\geq 40$ & $27(26.2)$ & $27(17.0)$ & $29(13.1)$ & $23(18.9)$ \\
\hline Not reported & $2(1.9)$ & $1(0.6)$ & $2(0.9)$ & 0 \\
\hline ICU bed percentage & $11.0 \pm 9.9$ & $12.0 \pm 20.9$ & $9.9 \pm 7.1$ & $15.2 \pm 17.6$ \\
\hline ICU clinical nurse specialist present & $42(40.8)$ & $63(39.9)$ & $80(36.0)$ & $51(41.8)$ \\
\hline ICU medical director present & $75(73.5)$ & $92(58.6)$ & $121(54.8)$ & $86(71.1)$ \\
\hline
\end{tabular}

Data presented as number (percentage) or mean \pm standard deviation. 
Table 2 Survey hospital visiting hour policies, by hospital location

\begin{tabular}{lll}
\hline \multirow{2}{*}{ Category } & \multicolumn{2}{l}{ Hospital location } \\
\cline { 2 - 3 } & Hospital-wide & ICU \\
\hline Any restriction present & $463(76.4)$ & $543(89.6)$ \\
Number of restrictions (maximum of 5) & $1.4 \pm 1.2$ & $2.8 \pm 1.5$ \\
Restrictions present & & \\
$\quad$ Visiting hours & $448(75.2)$ & $487(80.4)$ \\
$\quad$ Visit duration & $42(7.1)$ & $239(39.4)$ \\
$\quad$ Visitor number & $134(22.5)$ & $408(67.3)$ \\
Immediate family members & $23(3.9)$ & $147(24.3)$ \\
$\quad$ Based on visitor age & $160(26.9)$ & $387(63.9)$ \\
Allow exceptions to policy & - & $474(94.8)$ \\
$\quad$ Visiting hours & - & $410(82.8)$ \\
$\quad$ Visit duration & - & $222(44.9)$ \\
$\quad$ Visitor number & - & $372(75.2)$ \\
Immediate family members & - & $132(26.7)$ \\
$\quad$ Based on visitor age & - & $332(66.8)$ \\
\hline
\end{tabular}

Data presented as number (percentage) or mean \pm standard deviation.

The majority of hospitals had restrictive hospital $(n=$ $463,76.4 \%)$ and ICU $(n=543,89.6 \%$ visitation policies (Table 2). The mean numbers of restrictions were $1.4 \pm$ 1.2 and $2.8 \pm 1.5$, respectively. Most ICUs had three or more restrictions $(n=375,61.9 \%)$. The most common restrictions were related to visiting hours, followed by visitor number and age. Exceptions to the visitation policies were permitted in $94.8 \%$ of the ICUs. Within facilities, the correlation between the number of hospital and ICU visitation restrictions was moderate (correlation coefficient, 0.39). Figure 1 shows the distribution of ICU visitation restrictions based on hospital bed size and ICU bed percentage. Hospitals with fewer than 150 beds more frequently had open ICU visitation policies when compared with larger hospitals $\left(16.8 \%\right.$ vs. $5.1 \%$; $\chi^{2}$ $P<0.001$ ).

However, hospital bed size was not significantly associated with the number of ICU restrictions (Table 3); neither were hospital type, number of critical care units, or the presence of ICU leadership. Only the US region and ICU bed percentage were statistically significant in linear regression analysis; however, the effect size associated with ICU bed percentage was small $(-0.03$ for each percentage increase; $95 \%$ confidence interval, -0.05 to $-0.002 ; P=0.03)$. On average, hospitals in the Midwest had the least restrictive policies while those in the Northeast had the most restrictive.

\section{Discussion}

In this survey of US hospitals, we found that their overwhelming default policy was to restrict ICU visitation. Among ICUs with restrictive policies, there was a high degree of variability in the number of restrictions and no significant association with hospital size or type, number of critical care wards, or leadership roles. The ICU policies were only moderately correlated with hospital-wide policies. In practice, however, nearly all ICUs allowed some exceptions to their visitation restrictions. Only a fraction of ICUs had open visitation policies and these were more common among small hospitals.

Critically ill patients often suffer from life-threatening disease and multisystem organ failure [12]. As a result, the modern ICU has evolved into a highly specialized unit designed to facilitate rapid diagnosis, continuous monitoring, and prompt delivery of multidisciplinary, multimodal, and technologically advanced therapies [13]. The results have been extraordinary, with patient survival steadily improving over time [14-16]. Because of the complexity of ICU care, prior small studies have raised concerns that open ICU visitation policies could harm patients by increasing physiologic stress, interfering with timely and safe care delivery, infringing on patient privacy, increasing exposure to infection, leading to caregiver exhaustion, and negatively impacting interactions with families [4,17-26].

Given these concerns, our finding that the majority of ICUs had restrictive and highly variable policies is not surprising. Prior studies have found similar results in US ICUs and international ICUs [6-10,21,26-28]. A survey among 171 hospitals in New England found that 32\% had unrestricted visiting hours; however, most had restrictions on the age and number of visitors allowed [10]. Another survey of US ICUs, conducted by the American Association of Critical Care Nurses, also found high degrees of variability in visitation practice [9]. Giannini and colleagues reported that only a single Italian ICU, out of 257 surveyed, allowed open visitation [8]. No Belgian ICU, in a study by Spreen and Schuurmans, had an open visitation policy - defined as no restrictions on visiting hours, visit duration, and/or number of visitors [28]. Hunter and colleagues reported that $80 \%$ of ICUs in the United Kingdom imposed restricted visiting policies; they also noted wide variations in specific practices [27].

However, while historical practice among ICUs appears to have been to restrict visitation and we have seen concurrent substantial improvements in short-term mortality, new challenges in critical care have arisen. Survivors of critical illness and intensive care can suffer from post-intensive care syndrome - a condition whose sequelae include post-traumatic stress disorder as well as long-term physical and neurocognitive disability $[1,2,29]$. Furthermore, critical illness not only afflicts ICU patients, it also impacts patients' families [3,30-33]. Family members often struggle with decisions about their loved ones' end-of-life care and can, themselves, experience depression, anxiety, and posttraumatic stress disorder [3,30-35]. Visitation restrictions 


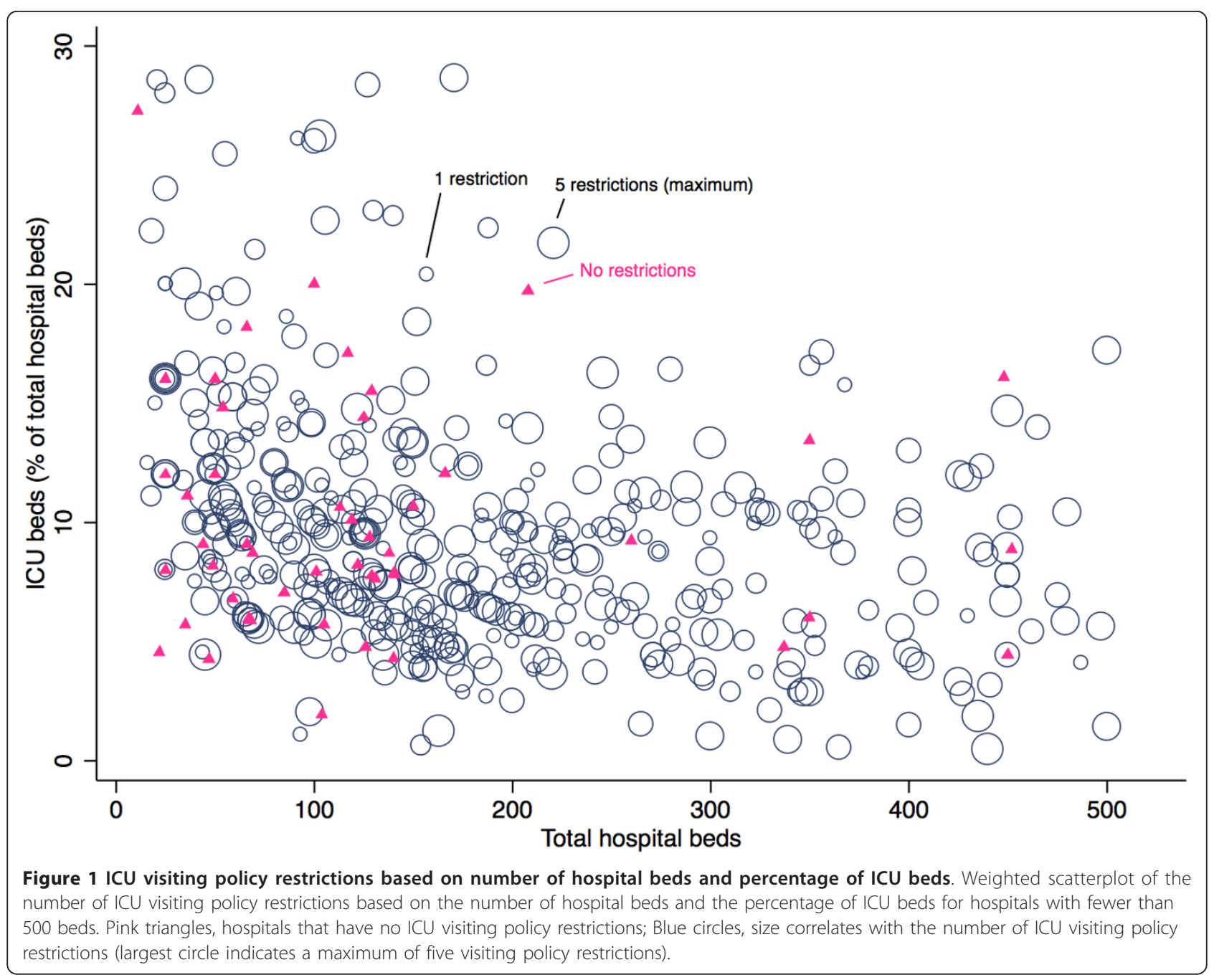

can thus further contribute to patients' and families' experiences of ICUs as disorienting places that enforce separation during challenging periods of critical illness and recovery [3,34-36].

As a result, numerous stakeholders and healthcare leaders have recommended liberalizing ICU visitation; Berwick and Kotagal declared restricted visiting practices as 'neither caring, compassionate, nor necessary' [3,5,37]. In 2010, US President Barack Obama also called on hospitals to foster open visitation policies [38]. Recent data suggest that open visitation policies do not adversely impact patient outcomes and represent only a moderate, and acceptable, intrusion on patient care [3,39-45]. Furthermore, family-centered care in the ICU is associated with improvements in the long-term psychiatric sequelae of critical illness, the trust between hospital staff and family members, and overall satisfaction with medical care $[2,3,35]$. Several studies also demonstrate the promise of interventions designed to provide families with a guided tour through the complexities of critical illness and to teach them how they can safely participate in ICU care [32,46-48].

Despite these reported benefits, we found that few ICUs had open visitation policies and they were more commonly located in small hospitals. Where ICUs had restrictive policies, we found wide variability in practice. Besides broad regional differences in ICU policies, other hospital characteristics were not strongly associated with the number of visitation restrictions. Instead, policies appeared to be distributed among hospitals without a clear pattern and probably reflect historical practices rather than evidence-driven decision-making [4]. Recent studies suggest that ICUs are actively rethinking their visitation policies to move towards more liberal visitation policies - a shift in the United States that has been supported by healthcare accreditation and regulatory agencies including the Joint Commission and the Center for Medicare \& Medicaid Services among others $[4,8,49]$.

Our findings should be interpreted in light of the study's limitations. First, the survey was conducted in 
Table 3 Variables associated with number of ICU visiting policy restrictions in univariable/multivariable linear regression models

\begin{tabular}{|c|c|c|}
\hline \multirow[b]{2}{*}{ Variable } & \multicolumn{2}{|c|}{ Point estimate from linear regression } \\
\hline & Univariable & Multivariable \\
\hline Hospital size, per 100 beds & $0.04(-0.02$ to 0.10$)$ & $0.01(-0.10$ to 0.11$)$ \\
\hline ICU bed percentage, per $\%$ & $-0.02(-0.04$ to -0.01$)$ & $-0.03(-0.05$ to 0.00$)$ \\
\hline ICU number, per ICU & $0.01(-0.07$ to 0.08$)$ & $-0.04(-0.15$ to 0.08$)$ \\
\hline \multicolumn{3}{|l|}{ Region } \\
\hline Midwest (reference) & - & - \\
\hline Northeast & 0.91 (0.52 to 1.30$)$ & $0.83(0.43$ to 1.23$)$ \\
\hline South & $0.84(0.53$ to 1.15$)$ & $0.85(0.53$ to 1.17$)$ \\
\hline West & $0.53(0.17$ to 0.90$)$ & 0.54 (0.18 to 0.91$)$ \\
\hline \multicolumn{3}{|l|}{ Hospital type } \\
\hline Community (reference) & - & - \\
\hline Government & $0.13(-0.20$ to 0.46$)$ & $0.16(-0.17$ to 0.49$)$ \\
\hline University & $0.08(-0.29$ to 0.46$)$ & $0.25(-0.29$ to 0.79$)$ \\
\hline ICU medical director present & $0.18(-0.08$ to 0.44$)$ & $0.19(-0.08$ to 0.47$)$ \\
\hline Clinical nurse specialist present & $0.06(-0.20$ to 0.32$)$ & $0.08(-0.19$ to 0.36$)$ \\
\hline
\end{tabular}

Data in parentheses are $95 \%$ confidence interval. Bold data are statistically significant, $P<0.05$. Multivariable linear regression model adjusted for all displayed variables.

2008 and 2009. Given the increasing public awareness and unified sentiment that appear to favor open visitation policies since that time, a contemporary assessment of ICUs is urgently needed to determine whether policies have changed and what factors impact such changes. Second, while we sampled a large number of ICUs with high response rates, this survey represents the practices of fewer than $25 \%$ of US ICUs. Finally, additional factors that could influence ICU visitation policy (for example, the physical size of each ICU room, the presence of waiting rooms, the duration of visit times allowed) were not evaluated in this study and may offer additional insight into understanding the wide observed variability in practice across centers.

\section{Conclusion}

The overwhelming majority of US ICUs in this study had restrictive visitation policies. While there were regional differences in ICU policies and open policies were common in smaller hospitals, other hospital characteristics were not strongly associated with the number of visitation restrictions. Wide variability in visitation policies suggests that further study into the impact of ICU visitations on patients and families are likely to influence and improve future practice.

\section{Key messages}

- The majority of ICUs in the United States had restrictive visitation policies based on survey results from over 600 hospitals between 2008 and 2009.

- Hospitals in the Midwest region had the most liberal policies while smaller hospitals more frequently had open visitation policies.
- Hospital characteristics - including bed size, number of critical care units, presence of ICU leadership, and hospital type - were not associated with the number of visitation restrictions

- There was wide variability in ICU visitation policies and practices across a broad range of surveyed hospitals.

\section{Authors' contributions}

$V L$ had full access to all of the data in the study and takes responsibility for the integrity of the data and the accuracy of the data analysis - he participated in the conduct of the study; analysis and interpretation of the data; and preparation, review, and approval of the manuscript. JLR participated in the design and conduct of the study; collection, management, and interpretation of the data; and preparation, review, and approval of the manuscript. ES participated in the design and conduct of the study; collection, management, analysis, and interpretation of the data; and preparation, review, and approval of the manuscript. EC participated in the design and conduct of the study; collection, management, and interpretation of the data; and preparation, review, and approval of the manuscript. All authors read and approved the final manuscript for publication.

\section{Competing interests}

The authors declare that they have no competing interests.

\section{Acknowledgements}

This work was funded by the Kaiser Foundation Research Institute and The Permanente Medical Group, Inc. The sponsors of the study had no role in the design and conduct of the study; in the collection, management, analysis, and interpretation of the data; and in the preparation, review, or approval of the manuscript. Portions of this work were presented at the Society of Critical Care Medicine Congress in 2010. Carly Skeath, Elena Corona, and Colleen Connell participated in conducting the telephone surveys; and Lue-Yen Tucker participated in the hospital survey sampling design.

\section{Author details}

'Kaiser Permanente Division of Research and Systems Research Initiative, 2000 Broadway (Webster Annex), Oakland, CA 94612, USA. ${ }^{2}$ Kaiser 
Permanente Fremont Medical Center, 39400 Paseo Padre Parkway, Fremont, CA 94538, USA. ${ }^{3}$ Kaiser Permanente Regional Quality and Regulatory Services, 1950 Franklin Street, Oakland, CA 94612, USA. "Kaiser Permanente San Jose Medical Center, 250 Hospital Parkway, San Jose, CA 95119, USA.

Received: 15 January 2013 Revised: 25 March 2013

Accepted: 11 April 2013 Published: 16 April 2013

\section{References}

1. Angus DC, Carlet J: Surviving intensive care: a report from the 2002 Brussels Roundtable. Intensive Care Med 2003, 29:368-377.

2. Needham DM, Davidson J, Cohen H, Hopkins RO, Weinert C, Wunsch H, Zawistowski C, Bemis-Dougherty A, Berney SC, Bienvenu OJ, Brady SL, Brodsky MB, Denehy L, Elliott D, Flatley C, Harabin AL, Jones C, Louis D, Meltzer W, Muldoon SR, Palmer JB, Perme C, Robinson M, Schmidt DM, Scruth E, Spill GR, Storey CP, Render M, Votto J, Harvey MA: Improving long-term outcomes after discharge from intensive care unit: report from a stakeholders' conference. Crit Care Med 2012, 40:502-509.

3. Davidson JE, Powers K, Hedayat KM, Tieszen M, Kon AA, Shepard E, Spuhler V, Todres ID, Levy M, Barr J, Ghandi R, Hirsch G, Armstrong D, American College of Critical Care Medicine Task Force 2004-2005, Society of Critical Care Medicine: Clinical practice guidelines for support of the family in the patient-centered intensive care unit: American College of Critical Care Medicine Task Force 2004-2005. Crit Care Med 2007, 35:605-622.

4. Berwick DM, Kotagal M: Restricted visiting hours in ICUs: time to change. JAMA 2004, 292:736-737.

5. The Joint Commission: Advancing Effective Communication, Cultural Competence, and Patient- and Family-centered Care: A Roadmap for Hospitals Oakbrook Terrace, IL: The Joint Commission; 2010.

6. Simon SK, Phillips K, Badalamenti S, Ohlert J, Krumberger J: Current practices regarding visitation policies in critical care units. Am J Crit Care 1997, 6:210-217.

7. Vandijck DM, Labeau SO, Geerinckx CE, De Puydt E, Bolders AC, Claes B, Blot SI: An evaluation of family-centered care services and organization of visiting policies in Belgian intensive care units: a multicenter survey. Heart Lung 2010, 39:137-146.

8. Giannini A, Miccinesi G, Leoncino S: Visiting policies in Italian intensive care units: a nationwide survey. Intensive Care Med 2008, 34:1256-1262.

9. Kirchhoff KT, Dahl N: American Association of Critical-Care Nurses' national survey of facilities and units providing critical care. Am J Crit Care 2006, 15:13-27.

10. Lee MD, Friedenberg AS, Mukpo DH, Conray K, Palmisciano A, Levy MM: Visiting hours policies in New England intensive care units: strategies for improvement. Crit Care Med 2007, 35:497-501.

11. Carr BG, Addyson DK, Kahn JM: Variation in critical care beds per capita in the United States: implications for pandemic and disaster planning. JAMA 2010, 303:1371-1372.

12. Ferreira FL, Bota DP, Bross A, Melot C, Vincent JL: Serial evaluation of the SOFA score to predict outcome in critically ill patients. JAMA 2001, 286:1754-1758.

13. Weil MH, Tang W: From intensive care to critical care medicine: a historical perspective. Am J Respir Crit Care Med 2011, 183:1451-1453.

14. Kvale R, Flaatten H: Changes in intensive care from 1987 to 1997 - has outcome improved? A single centre study. Intensive Care Med 2002, 28:1110-1116.

15. Levy MM, Dellinger RP, Townsend SR, Linde-Zwirble WT, Marshall JC, Bion J, Schorr C, Artigas A, Ramsay G, Beale R, Parker MM, Gerlach H, Reinhart K, Silva E, Harvey M, Regan S, Angus DC, Surviving Sepsis Campaign: The Surviving Sepsis Campaign: results of an international guideline-based performance improvement program targeting severe sepsis. Crit Care Med 2010, 38:367-374.

16. Li G, Malinchoc M, Cartin-Ceba R, Venkata CV, Kor DJ, Peters SG Hubmayr RD, Gajic O: Eight-year trend of acute respiratory distress syndrome: a population-based study in Olmsted County, Minnesota. Am J Respir Crit Care Med 2011, 183:59-66.

17. Adams $S$, Herrera A, Miller $L$, Soto R: Visitation in the intensive care unit: impact on infection prevention and control. Crit Care Nurs Q 2011, 34:3-10

18. Biancofiore G, Bindi LM, Barsotti E, Menichini S, Baldini S: Open intensive care units: a regional survey about the beliefs and attitudes of healthcare professionals. Minerva Anestesiol 2010, 76:93-99.
19. Tang CS, Chung FF, Lin MC, Wan GH: Impact of patient visiting activities on indoor climate in a medical intensive care unit: a 1-year longitudinal study. A J Infect Control 2009, 37:183-188.

20. Garrouste-Orgeas M, Philippart F, Timsit JF, Diaw F, Willems V, Tabah A, Bretteville G, Verdavainne A, Misset B, Carlet J: Perceptions of a 24-hou visiting policy in the intensive care unit. Crit Care Med 2008, 36:30-35.

21. Berti D, Ferdinande P, Moons P: Beliefs and attitudes of intensive care nurses toward visits and open visiting policy. Intensive Care Med 2007, 33:1060-1065.

22. Livesay S, Gilliam A, Mokracek M, Sebastian S, Hickey JV: Nurses' perceptions of open visiting hours in neuroscience intensive care unit. J Nurs Care Qual 2005, 20:182-189.

23. Farrell ME, Joseph DH, Schwartz-Barcott D: Visiting hours in the ICU: finding the balance among patient, visitor and staff needs. Nurs Forum 2005, 40:18-28.

24. Foss KR, Tenholder MF: Expectations and needs of persons with family members in an intensive care unit as opposed to a general ward. South Med J 1993, 86:380-384.

25. Soury-Lavergne A, Hauchard I, Dray S, Baillot ML, Bertholet E, Clabault K, Jeune S, Ledroit C, Lelias I, Lombardo V, Maetens Y, Meziani F, Reignier J, Souweine B, Tabah A, Barrau K, Roch A, Société de Réanimation de Langue Française: Survey of caregiver opinions on the practicalities of familycentred care in intensive care units. J Clin Nurs 2012, 21:1060-1067.

26. Knutsson SE, Otterberg CL, Bergbom IL: Visits of children to patients being cared for in adult ICUs: policies, guidelines and recommendations. Intensive Crit Care Nurs 2004, 20:264-274

27. Hunter JD, Goddard C, Rothwell M, Ketharaju S, Cooper H: A survey of intensive care unit visiting policies in the United Kingdom. Anaesthesia 2010, 65:1101-1105.

28. Spreen $A E$, Schuurmans MJ: Visiting policies in the adult intensive care units: a complete survey of Dutch ICUs. Intensive Crit Care Nurs 2011, 27:27-30.

29. Iwashyna TJ, Netzer G: The burdens of survivorship: an approach to thinking about long-term outcomes after critical illness. Semin Respir Crit Care Med 2012, 33:327-338

30. Davydow DS, Hough CL, Langa KM, Iwashyna TJ: Depressive symptoms in spouses of older patients with severe sepsis. Crit Care Med 2012, 40:2335-2341.

31. Azoulay E, Pochard F, Kentish-Barnes N, Chevret S, Aboab J, Adrie C Annane D, Bleichner G, Bollaert PE, Darmon M, Fassier T, Galliot R, Garrouste-Orgeas M, Goulenok C, Goldgran-Toledano D, Hayon J, Jourdain M, Kaidomar M, Laplace C, Larché J, Liotier J, Papazian L, Poisson C, Reignier J, Saidi F, Schlemmer B, FAMIREA Study Group: Risk of post-traumatic stress symptoms in family members of intensive care unit patients. Am J Respir Crit Care Med 2005, 171:987-994.

32. Jones C, Skirrow P, Griffiths RD, Humphris G, Ingleby S, Eddleston J, Waldmann C, Gager M: Post-traumatic stress disorder-related symptoms in relatives of patients following intensive care. Intensive Care Med 2004, 30:456-460.

33. Siegel MD, Hayes E, Vanderwerker LC, Loseth DB, Prigerson HG: Psychiatric illness in the next of kin of patients who die in the intensive care unit. Crit Care Med 2008, 36:1722-1728

34. Davidson JE, Jones C, Bienvenu OJ: Family response to critical illness: postintensive care syndrome-family. Crit Care Med 2012, 40:618-624.

35. Family presence: visitation in the adult ICU. Crit Care Nurse 2012, 32:76-78.

36. Abbott KH, Sago JG, Breen CM, Abernethy AP, Tulsky JA: Families looking back: one year after discussion of withdrawal or withholding of lifesustaining support. Crit Care Med 2001, 29:197-201.

37. Hamner JB: Visitation policies in the ICU: a time for change. Crit Care Nurse 1990, 10:48-53.

38. Presidential Memorandum - Hospital Visitation. [http://www.whitehouse gov/the-press-office/presidential-memorandum-hospital-visitation]

39. Hepworth JT, Hendrickson SG, Lopez J: Time series analysis of physiological response during ICU visitation. West J Nurs Res 1994, 16:704-717.

40. Giuliano KK, Bloniasz E, Bell J: Implementation of a pet visitation program in critical care. Crit Care Nurse 1999, 19:43-50

41. Lewin SA, Skea ZC, Entwistle V, Zwarenstein M, Dick J: Interventions for providers to promote a patient-centred approach in clinical consultations. Cochrane Database Syst Rev 2001, 4:CD003267. 
42. Slota M, Shearn D, Potersnak K, Haas L: Perspectives on family-centered, flexible visitation in the intensive care unit setting. Crit Care Med 2003, 31:S362-S366.

43. Fox-Wasylyshyn SM, El-Masri MM, Williamson KM: Family perceptions of nurses' roles toward family members of critically ill patients: a descriptive study. Heart Lung 2005, 34:335-344.

44. Biancofiore G, Bindi LM, Traballoni L, Cristofano M: Liberalization of visiting policies in the ICU: it is also a matter of good information. Intensive Care Med 2008, 34:2312.

45. Kleinpell RM: Visiting hours in the intensive care unit: more evidence that open visitation is beneficial. Crit Care Med 2008, 36:334-335.

46. Jones C, Backman C, Griffiths RD: Intensive care diaries and relatives' symptoms of posttraumatic stress disorder after critical illness: a pilot study. Am J Crit Care 2012, 21:172-176.

47. Davidson JE: Facilitated sensemaking: a strategy and new middle-range theory to support families of intensive care unit patients. Crit Care Nurse 2010, 30:28-39.

48. Lautrette A, Darmon M, Megarbane B, Joly LM, Chevret S, Adrie C, Barnoud D, Bleichner G, Bruel C, Choukroun G, Curtis JR, Fieux F, Galliot R, Garrouste-Orgeas M, Georges H, Goldgran-Toledano D, Jourdain M,

Loubert G, Reignier J, Saidi F, Souweine B, Vincent F, Barnes NK, Pochard F, Schlemmer B, Azoulay E: A communication strategy and brochure for relatives of patients dying in the ICU. N Engl I Med 2007, 356:469-478,

49. Giannini A, Marchesi T, Miccinesi G: Andante moderato: signs of change in visiting policies for Italian ICUs. Intensive Care Med 2011, 37:1890.

doi:10.1186/cc12677

Cite this article as: Liu et al:: Visitation policies and practices in US ICUs. Critical Care 2013 17:R71.

\section{Submit your next manuscript to BioMed Central and take full advantage of:}

- Convenient online submission

- Thorough peer review

- No space constraints or color figure charges

- Immediate publication on acceptance

- Inclusion in PubMed, CAS, Scopus and Google Scholar

- Research which is freely available for redistribution

Submit your manuscript at www.biomedcentral.com/submit 